\title{
Steps Toward Massage Therapy Guidelines: A First Report to the Profession
}

Keith Eric Grant PhD, ${ }^{1}$ John Balletto Bs LMt, ${ }^{2}$ Donelda Gowan-Moody BA(Hons) RMT $^{3}$ Dale Healey BS DC, ${ }^{4}$ Diana Kincaid LMP, ${ }^{5}$ Whitney Lowe LMT, ${ }^{6}$ and Ravensara S. Travillian PhD LMP ${ }^{7}$

McKinnon Institute LLC, ${ }^{1}$ Oakland, CA, USA; Center for Muscular Therapy, Inc., ${ }^{2}$ Pawtucket, RI, USA; Department of Community Health and Epidemiology, ${ }^{3}$ University of Saskatchewan, Saskatoon, SK, Canada; Northwestern Health Sciences University, ${ }^{4}$ Bloomington, MN, USA; Lymphatic Integrative Therapy and Training, ${ }^{5}$ Seattle, WA, USA; Orthopedic Massage Education and Research Institute, ${ }^{6}$ Sisters, OR, USA; Structural Informatics Group, ${ }^{7}$ University of Washington, Seattle, WA, USA

The massage profession has grown rapidly since the late 1980s. As with business startups that begin informally and successfully mature into larger enterprises, growth brings new organizational challenges, together with greater visibility and opportunity. The maturation of massage as a health care profession increases the need for a process to formalize the synthesis of massage therapy knowledge from clinical experience and research-to collect what we know and to make such baseline knowledge widely available to practitioners, consumers, and other health care stakeholders. In short, we need to create a process for setting guidelines.

The present paper lays out the motivations and framework for creating massage therapy guidelines that are informed both by research and by clinical experience. It also acts as a report to the massage therapy profession and to other stakeholders about the work of the Best Practices Committee of the Massage Therapy Foundation since 2006. And it has the additional goal of providing a health care literature basis for future academic discussions of massage.

The discussion here is based on a definition from the Institute of Medicine and on research into the nature of expertise. Guidelines are targeted for submission to the National Guideline Clearinghouse. Challenges in creating guidelines for massage therapy are discussed. Various stakeholders are considered. Current literature from the wider scope of health care is extensively reviewed. Topics addressed include guideline creation, credentialing of complementary and alternative medicine practitioners, definition of competence, and the increasing role of technology (that is, informatics) in managing training and task-necessary competencies. Finally, a process for creation of massage therapy guidelines is proposed. A central feature of the proposal is the use of a "World Café" symposium to elicit knowledge and solutions from diverse experts. The role of transparency and broad and open peer review is emphasized as essential to the usability and credibility of guidelines.

KEYWORDS: Massage, practice guideline, evidence-based medicine, informatics, competency-based education, professional competence, credentialing, case management

\section{INTRODUCTION}

The massage profession has grown rapidly since the late 1980s. As with business startups that begin informally and successfully mature into larger enterprises, growth brings new organizational challenges, together with greater visibility and opportunity. The public recognition of massage therapy as a means of increasing health and well-being has brought increasing use. The increasing use of massage as an element of health and wellness care has attracted more attention from established health professions, health care case managers, legislators, and liability attorneys. The maturation of massage as a health care profession increases the need for a process to formalize the synthesis of massage therapy knowledge from clinical experience and research - that is, to collect what we know and to make such baseline knowledge widely available to practitioners, consumers, and other health care stakeholders. In short, we need to create a process for creating guidelines.

This need arises, as will be discussed, not just in the context of changes in the massage profession itself, but within larger contexts of increased use of complementary and alternative medicine (CAM) overall, of change and self-reflection throughout the health care professions, and of changes that information technology is bringing into knowledge and competency management. Massage therapy is not just an old profession newly grown, but a profession entered into the 21st century. In considering guidelines, we are much less 
traveling toward a fixed "mountain," than joining others traveling on a high-speed moving walkway.

The intrinsic growth in the use of massage therapy has come atop overall growth in the use of CAM therapies. Eisenberg et al. ${ }^{(1,2)}$ reported on the continued growth of CAM use in the United States. Expenditures associated with use of unconventional therapy in 1990 amounted to approximately $\$ 13.7$ billion, three quarters of which (\$10.3 billion) were paid out-of-pocket. Estimated expenditures for alternative medicine professional services increased $45.2 \%$ between 1990 and 1997 and were conservatively estimated at $\$ 21.2$ billion in 1997, with at least $\$ 12.2$ billion paid out-of-pocket. Barnes et al. ${ }^{(3)}$ reported results from a 2002 US survey indicating that $36 \%$ of adults used some form of CAM therapy (excluding prayer) during the past 12 months. Separate surveys by the Associated Bodywork and Massage Professionals (ABMP) ${ }^{(4)}$ and the American Massage Therapy Association (AMTA) ${ }^{(5)}$ estimated that massage therapy is a \$6- to \$15-billion industry (annual figures). The AMTA results suggested that "between August 2006 and June 2007 almost a quarter of adult Americans (24 percent) had a massage at least once in the last 12 months." The ABMP data estimated that "sixteen percent of U.S. adults visited a massage therapist [(MT)] in 2006 and 38 percent have received a professional massage sometime in their life."

In 1999, the Fraser Institute published the first-ever comprehensive study of Canadians' use of and public attitudes to CAM. In 2007, a new study was published by the Fraser Institute to capture any changes that had occurred $^{(6)}$. Canadians spent an estimated $\$ 7.8$ billion out-of-pocket on alternative medicine in the latter half of 2005 and first half of 2006, which is a significant increase from the nearly $\$ 5.4$ billion (inflation-adjusted) estimated to have been spent in the latter half of 1996 and first half of 1997. Despite incurring large out-ofpocket expenses, most Canadians believe that alternative therapies should be paid for privately and not by provincial health plans.

In 2006, more than one half of surveyed Canadians (54\%) reported using at least one alternative therapy in the year preceding the survey. By 2006, 35\% of Canadians had tried massage - a significant increase of 12 percentage points from 1997. Massage therapy was the most common CAM used over the preceding year, having been used by $19 \%$ of respondents. Average outof-pocket spending for those using massage therapy over the preceding 12 months increased from \$211 in 1997 to $\$ 365$ in 2006. Questions on use of CAM for specific conditions indicated that, if given $\$ 100$ for treatment of low back pain, study respondents would have spent, on average, $\$ 31$ for surgery, $\$ 30$ for chiropractic treatment, and $\$ 40$ for massage and exercise therapies. Thus, massage therapy has a pattern of significant and rising use among Canadians.

From a statistical viewpoint, the overall growth in use of massage therapy has led to increased breadth and depth of clinical experience-the possibilities of use have simply been "sampled" to a greater extent. More practitioners are using massage as a means of intervention for specific conditions. More MTs are also practicing in a greater variety of health care contexts ${ }^{(2,6-8)}$. The greater use and greater visibility of massage therapy has also motivated more research on effectiveness and means of use. Yet, often, knowledge from both clinical experience and research has continued to remain diffusely known and obscure. It can be a research effort in itself to determine the best available knowledge on an application of massage therapy or on massage in the presence of a comorbidity. It is this challenge of synthesis of knowledge that the Massage Therapy Foundation's Best Practices Committee (BPC) is seeking to address.

The goal of the BPC is to develop a conceptual structure of evidence-based best practices for massage therapy. As a matter of clear definition, throughout this paper the term "evidence-based" is taken to include information from (practice informed by) both research and clinical experience. Also worth noting at the outset is the distinction and separability between direct observations and any theoretical model or mechanism advanced as an explanation of observations. Because little or no literature exists to provide a reference basis for such discussion in the context of massage, the present paper also has the additional goal of providing a health care literature basis for future academic discussions of massage.

The BPC intends that the conceptual structure presented and its underlying principles be used to develop guidelines, both general and specific, to be made available to MTs, massage therapy regulators, health care managers, educators, and clients in their respective arenas. Simply put, "best practice guidelines” are the collection, representation, and communication of current approaches and methods that have yielded positive patient/client outcomes. They are educational and informative for members of the profession and for the public and other health care providers. A central feature of the proposal is the use of a "World Café" symposium to elicit knowledge and solutions from diverse experts. The symposium would be aimed at vetting and refining the proposed guideline process by applying it to creation of guidelines for massage interventions for stress management, low back pain, and lymphedema. Before the symposium, participants would be informed of the symposium goals and process and on available research pertinent to the guidelines being considered. After the symposium, tasks to be carried out would include transcription of recordings, concept mapping(9), elicited-knowledge synthesis, and circulating the synthesis and background documentation. Accuracy would be checked with symposium participants and then a request for comments (RFC) would be issued to all stakeholders. The synthesis would be iteratively refined based on comments received. The role of transparency and openness of 
the stakeholder review is emphasized as essential to the usability and credibility of the guidelines.

Before turning to a more detailed discussion of guidelines and their prospective benefits, a summary of several stakeholder considerations provides more context to the BPC efforts. The more detailed look at parallel health care efforts on guidelines and informatics is also held until after the massage context is better defined.

- Medical professionals have expressed concern over determining the appropriateness of a referral for specific treatment and the potential malpractice liability associated with such referral ${ }^{(10-12)}$. In the rare cases of serious injury subsequent to a massage $\operatorname{session}^{(13,14)}$, the lack of clear guidelines as a reference has made it difficult to determine whether the injury resulted from practitioner negligence or whether it was effectively idiopathic — able to be triggered by activities of daily life, including massage therapy.

- In the arena of occupational regulation, legislators have a responsibility to determine the level of regulation that is necessary and sufficient for the public benefit. Other manual health care professions often provide input to bills addressing massage governance, including content effectively consisting of medical opinions on the safety of massage. The lack of published, evidence-based guidelines for massage best practices makes it harder for legislators and their staffs to assess the evidence base and validity of such input.

- Patients/clients and third-party reimbursers have a stake in assessing whether a proposed massage treatment has been found effective for the medical condition and overall patient health context. In a context of client facilitation, it is sufficient that facilitation be safe and satisfactory to the client. In a health care context, however, the additional benchmark of effectiveness must also be met ${ }^{(12)}$. Additionally, a referring physician must be both knowledgeable and confident of such effective$\operatorname{ness}^{(7,8)}$

\section{WHAT ARE GUIDELINES?}

The National Guideline Clearinghouse (NGC) ${ }^{(15)}$ uses the definition of clinical practice guideline developed by the Institute of Medicine (IOM) ${ }^{(16)}$ and presented in a report on guidelines for guidelines by Field and $\operatorname{Lohr}^{(17)}$ (p. 38):

Clinical practice guidelines are systematically developed statements to assist practitioner and patient decisions about appropriate health care for specific clinical circumstances.

Basing our guidelines effort on the IOM definition clarifies that guidelines serve a mentoring role, not a regulatory role. Guidelines provide knowledge management for decentralized decision makers, be they individual practitioners or stakeholder health care agencies.

To be submitted to the NGC, guidelines are required to meet specified organizational origin and quality criteria. Guidelines are also generally subject to a review and comment process. By creating a synthesis of the best available information from clinical experience and research, and by capturing a record of discussion, guidelines and their background documentation encourage and guide the reflection and decisions of individual practitioners and of stakeholder agencies. A guideline process will not necessarily result in a single consensus of opinion, but it should result in a synthesis of knowledge that provides useful options for decisions. However, guidelines do not compel those decisions; the decision responsibility remains with the individual practitioners and stakeholder agencies. The ultimate worth of a guideline is its usefulness. If it is used and referenced by many, then it, of its own accord, becomes a standard of reference. As role models in synthesizing best available information and best practice, the BPC has chosen analysis agencies such as the IOM, the Pew Charitable Trusts ${ }^{(18)}$, and the Rand Corporation ${ }^{(19)}$, which hold reputations for being deliberately impartial.

To be useful, guidelines cannot be a simple encoding of rational rules. Capturing knowledge from clinical experience is vital to ensuring the usefulness of guidelines. To be useful, guidelines have to go beyond simple objective facts and rational sequences of actions; they have to encapsulate patterns and approaches of actual practice. Benner ${ }^{(20,21)}$, based on the Dreyfus model of skill acquisition $^{(22,23)}$, and her own studies of nursing expertise, emphasizes the importance of patterns of experience:

The rational-technical vision of performance is that of a practitioner or technical expert developing mastery of a body of knowledge and applying that knowledge in prespecified ways for prespecified outcomes. The rational-technical model does not account for development of relational, perceptual, or skillful comportment over time. It also does not account for the role of experiential learning in learning to practice in a dynamic, underdetermined, and complex practice such as nursing and medicine. A strict technical application of knowledge does not take into account the skills required for discerning the nature of the situation and its possibilities and constraints.

Benner's focus on the importance of clinical experience leading to patterns of expertise is substantiated by the field research reported by Klein ${ }^{(24)}$. That focus finds application in the cognitive methods documented by Crandall et al. ${ }^{(9)}$, in the current rethinking of medical education assessment reported by Epstein ${ }^{(25)}$, and in the IOM's health care quality initiative ${ }^{(26)}$. A process that brings clinical experience to the level of conscious principles and approaches is vital to creating useful guidelines. Benner ${ }^{(20)}$ again lays out the para- 
dox of expertise and the need to elicit conscious reflection to capture otherwise tacit knowledge:

Not all of the knowledge embedded in expertise can be captured in theoretical propositions, or with analytic strategies that depend on identifying all the elements that go into the decision. However, the intentions, expectations, meanings, and outcomes of expert practice can be described, and aspects of clinical knowhow can be captured by interpretive descriptions of actual practice.... Clinical knowledge is gained over time, and clinicians themselves are often unaware of their gains. Strategies are needed to make clinical know-how public so it can be extended and refined.

Klein $^{(24)}$ (pp. 39-40), in discussing Beth Crandall's research with nurses in a neonatal intensive care unit (NICU), provides a concrete example of the process Benner describes:

Beth found that one of the difficult decisions the nurses had to make was to judge when a baby was developing a septic condition-in other words, an infection. These infants weighed only a few pounds-some of them, the microbabies, less than two pounds. When babies this small develop an infection, it can spread through their entire body and kill them before the antibiotics can stop it. Noticing the sepsis as quickly as possible is vital. Somehow the nurses in the NICU could do this. They could look at a baby, even a microbaby, and tell the physician when it was time to start the antibiotics. Sometimes the hospital would do tests, and they would come back negative. Nevertheless, the baby went on antibiotics, and usually the next day the test would come back positive. This is the type of skilled decision making that interests us the most. Beth began by asking the nurses how they were able to make these judgments. "It's intuition," she was told, or else "through experience." And that was that. The nurses had nothing more to say about it. They looked. They knew. End of story.

Klein goes on to describe how Crandall, through extensive interviewing of the NICU nurses, was able to elicit and organize previously tacit patterns of cues. Many of the cues were not previously recorded in the medical literature, and many were contradictory to adult cues of infection. The nurses were found to unconsciously react to complex patterns of subtle cues occurring together rather than to simple cues. Crandall was later able to create training materials focused on the cues, and importantly, presented in their original stories so that the less-experienced nurses could see how the cues appeared in context.

The BPC anticipates that experienced MTs will also often be responding to tacit patterns of subtle multisensory input from communication and interaction with clients and from observation and palpation of their tissues. As with Crandall's research, eliciting such patterns and tacit knowledge will be important to a guidelines creation process.

Practice guidelines provide a framework to illustrate the intentionality and integrity of massage therapy in addition to appropriate treatment protocols, duration, frequency, and outcomes. They can also reflect patient problems and issues or concerns that confront MTs. Guidelines, however, are not intended either to replace the practitioner's judgment or to establish a "set in stone" protocol for individual patients with any particular set of symptoms. Guidelines inherently suggest tasks, thus the "vocabulary" of guidelines is drawn from knowledge, skills, and abilities in cognitive, perceptual, motor-control, and interpersonal domains. By providing a baseline of discussion, guidelines thus interact with wider discussions of performance management, such as those presented by Mager and Pipe ${ }^{(27)}$.

After two years of committee communication and a face-to-face meeting in Seattle in March 2007, the BPC has taken the initial steps toward development of a process for evidence-based practice guidelines. The guidelines would be supported by systematic peer review and clinical research, as available. By developing evidence-based guidelines that encompass and promote the broad range of practices that our profession utilizes, we will continue to define ourselves beyond just "insurable" treatment categories and will be able to maintain what is unique to our profession. The BPC envisions some of the expected outcomes of the dissemination of these guidelines to include

- increased understanding by other stakeholders of massage and the profession of massage therapy;

- greater confidence, respect, and pride by MTs in their education, ethical practice, and professional quality of care;

- heightened awareness of the complementary nature and integrative capacity of massage therapy for health care and wellness;

- strengthened motivation and basis for referrals and payments to MTs as a result of clearer and more precisely defined measures of care;

- recognition for a diversity of massage therapy approaches to client/patient care within the global perspective of health care and wellness; and

- continued awareness of massage practitioners for providing safe and responsible care to their clients/ patients.

This spirit of positive development underlies the motivations behind this effort toward creating evidencebased practice guidelines - guidelines drawing both on research and on experience.

\section{CHALLENGES SPECIFIC TO MASSAGE THERAPY}

In establishing an evidence-based consideration of massage relative to health care, multiple challenges 
must be dealt with. Among them are the diversity of massage techniques, philosophies, and contexts, and the evidence base itself. In the United States at least, not all that falls under a regulatory context of massage can be assumed to be health care system-related; a broad and diverse range of services can appropriately be considered client facilitation or client-directed somatic/sensory exploration. As part of a general set of health care system definitions, the construction of massage regulation in the United States has been based on a "wide-net" paradigm of touch practices rather than on an outcome competency paradigm. Addressing this situation, Rosen ${ }^{(28)}$ recently commented on the need for a more compactly defined knowledge and competency base for health care system inclusion.

In contrast, in some Canadian provinces, the tendency has been to define massage therapy (by a title protection and scope of practice definition act) as a profession intrinsically embedded within the provincial health care system. Canadian provision of massage therapy is thereby health care by definition. The Fraser Institute report ${ }^{(6)}$ carefully investigated the stated purpose for which Canadians sought MT care-from wellness management, to injury treatment and management of comorbid and chronic illness. As Rosen's analysis of development of the profession in the United States did, a report prepared for the Federation of Massage Therapy Regulatory Authorities of Canada by Gowan-Moody and Baskwill(29) provided an analysis of what those authors termed the "professionalization trajectory" in Canadian provinces.

Either within or outside of a health care system, the concept of wellness facilitation can be both complex and elusive. Wellness promotion can include diverse goals such as client satisfaction, improved athletic performance and reduced indicators of stress. Within services that would be associated with "wellness care," interventions can be any one or a combination of physiologic, sociologic, psycho-emotional, or spiritual. Each aspect can contribute to an elevated sense of wellbeing. Some of this diversity of responses and goals can also carry over into services more directly connected to health care treatment. Facilitations can be tissue-specific or systematic, addressing either physical injury and dysfunction, or psychological and emotional aftereffects of trauma.

Professionals working within a wellness-centered paradigm can struggle with the dearth of evidence on the diverse techniques and approaches of massage and how they specifically facilitate the achievement of wellness. Comparison of the results of applying various techniques can be further complicated by client responses to attentional and motivational input by the practitioner, by individualistic responses to sensory input and by systematic responses of the body as a whole. Mindell( ${ }^{(30)}$, for example, noted that client responses to psychotherapy can be as dependent on attitudinal aspects of the practitioner as on the particular techniques used. Client responses to the communicative and attitudinal skills of the medical practitioner were also a focus of Lown ${ }^{(31)}$. Brain- and sensory-based responses to intervention/facilitation are reviewed by Ornstein and Sobel ${ }^{(32,33)}$ and Rossi ${ }^{(34)}$. Moreover, the concept of wellness itself, while widespread, is only vaguely defined both by professionals and by the public. According to surveys conducted by AMTA and ABMP, a significant percentage of the American public visit MTs for "wellness," and yet most of these clients cannot define exactly what "wellness" means or when they feel "well” both on conscious and unconscious levels. An evidence-based approach to massage and the relationship of massage to wellness would aid in determining appropriate care and in understanding potential contraindications.

Such an evidence-based approach would have substantial research to draw upon that would allow at least a start on knowledge synthesis and management. Rossi provided an extensive review of concepts of the recently emerged field of psychoneuroimmunology ${ }^{(34)}$. Research by Melzack ${ }^{(35)}$ on phantom limb pain led him to postulate the existence of a "neuromatrix" or neurologic body analog. This concept is consistent with a view of the body-mind as a system (or network) of interacting psychological, emotional, sensory, and chemical/immune systems. Such a system responds to sensory input, but does so in a manner that is dependent both on the input and on its current state. Blakeslee and Blakeslee ${ }^{(36)}$ provided a lay review on recent neurologic research on integration and use of a sense of body, defining the process in terms of "body maps." This body-map view provides insight on massage intervention as buffering a system in positive homeostasis against negative changes or nudging an out-of-balance system toward such homeostasis.

Practitioner abilities for such interventions often are based on tacit knowledge and experience-based skills of sensory perception. Benner ${ }^{(20,21)}$ and Klein ${ }^{(24)}$ noted that expertise, a product of experience, allows the practitioner to act by unconscious pattern matching and mental prediction - both occurring below the level of conscious thought. In commenting on neurologic research and attempts at artificial intelligence, Hawkins ${ }^{(37)}$, founder of the Redwood Center for Theoretical Neuroscience, notes that the human mind has evolved with great capabilities to process sensory input, to detect patterns, and to prompt changes in output presentation. Such considerations particularly affect wellness massage, tissue-specific treatments, and education designed to result in development of expertise.

Thus, with massage therapy in particular, there is a need to define the context of treatment sufficiently to enable concrete discussions and review. Even within a well-defined context, the evidence for a clear determination can be inadequate. Batavia ${ }^{(38)}$ noted both a lack of original references and a substantial disagreement relating to massage contraindications. Such challenges heighten the need for this endeavor and ensure that the path will be a somewhat rocky one. Nonethe- 
less, by setting out evidence-based criteria for guidelines and a guideline creation process, by prioritizing contexts that would be maximally benefited by guidelines, and by highlighting the existing knowledge base and its strengths as well as its deficits, the work of this committee stands to benefit the profession, the individual practitioner, the other professional and regulatory stakeholders, and the public recipients of massage services. By ensuring that the defined processes have multidisciplinary inclusion and stipulations for wide review and input (with open documentation), the authority of the documents produced will extend beyond that of the committee itself. In that sense, the committee will act far more as shepherds of best practices than as creators of them.

\section{STAKEHOLDERS AND BENEFITS}

Practice guidelines would serve numerous audiences, some of which are specifically identified below. When supported by clinical research and extensive peer review, the guidelines will increase the credibility of the profession by promoting more predictable, higher quality, and potentially cost-effective care. Guidelines would become part of the knowledge management of the profession. They would result from the multi-step process of identifying sources of expertise, assaying the expected value gain from active knowledge management weighed against costs, extracting expert knowledge, codifying knowledge, and leading those benefiting from the knowledge to apply it ${ }^{(9,24)}$.

Practice guidelines would provide a framework for evaluation and treatment of the more common patient/ client problems, issues, and concerns that confront MTs. They would not be intended either to replace the practitioner's judgment or to establish a "set in stone" protocol for individual patients with any particular set of symptoms. In general, guidelines are principles that can be developed for any situation to determine a course of action and its success.

By providing safe, effective, and ethical choices for client care, practice guidelines would have the potential to improve the consistency and quality of patient care and thereby improve a patient's quality of life. They can offer explicit recommendations for practitioners uncertain about how to proceed, inform doctors unaware of the benefits to their patients, reassure practitioners about the appropriateness of their treatment choices, and offer assurance that the approach the practitioner is using is reasonable and well-founded. They can send a message of a profession's commitment to excellence and quality, which in turn may influence public policy and promote good will, political support, and increased practitioner revenues.

However, guidelines that are poorly written, reviewed, and researched may have the potential to harm the patient, the practitioner, and the profession. Guidelines that are inflexible, ineffective, wasteful, poorly worded, or opinionated could mislead, confuse, and compromise the quality of care received and the quality of care given. By contrast, a carefully developed practice guideline can offer a baseline of predictability within a profession. It can provide a framework by which others outside the profession could evaluate the quality of care that is provided.

For MTs, practice guidelines should be educational and informative. As such, they will provide clarity and confidence to massage practitioners in their practice and in communicating with the public and other health care providers.

For educators, both pre-professional and those involved in lifelong learning education, guidelines could help to shape curricular content. In pre-professional education, the guidelines not only would serve as clinical references, but also could serve as a means to assist in developing a logical, reflective, and deductive thought process that would assist students in their ability to think critically and adapt to patient/client needs in the clinical practice setting. For continuing educators, guidelines could serve as an introduction to clinical protocols dealing with specific client presentations. Additionally, they may serve as examples in the use of guidelines and of adjustments made during clinical practice as models upon which to base case reports and accompanying client experiences for publication.

For consumers, guidelines would add assurance that the health care they are receiving is safe, effective, and ethical. Practice guidelines would communicate currently accepted industry practices and the norms of ethical behavior and integrity in our profession.

For health care providers in general, guidelines would provide context-specific information on the safety and efficacy of massage, helping them to interact effectively and appropriately in the best interests of their patients.

\section{STAKEHOLDER SCENARIOS}

To demonstrate the application of guidelines in realistic practice contexts, scenarios involving various stakeholders are presented here. These scenarios are a selected few among the many possible; in real clinical contexts, they demonstrate the information need that evidence-based best practice guidelines are intended to address. The "effect" discussions are intended to be exemplary of guideline results and benefits rather than being definitive statements in themselves.

\section{Massage Practitioners and the Profession}

\section{Scenario 1}

A recently-graduated massage practitioner is asked by a brand-new patient with cancer pain for palliative massage treatment. The practitioner looks for research literature to help with the clinical decision and finds conflicting information: Corbin ${ }^{(39)}$ clearly articulates concerns that massage may have risks associated with 
its use in the population of oncology patients, identifying disorders of coagulation (low platelet count; risk of hemorrhage because of treatment with warfarin, heparin, or aspirin), metastatic cancer in bones, open wounds, and radiation dermatitis as situations with potential for massage-related adverse events. Yet Ernst's review ${ }^{(13)}$ concludes that, although serious injuries from massage are possible, they are a true rarity. After reviewing the literature, the practitioner is as unsure about how to proceed as before.

The need: In the United States, massage school advice relative to cancer patients has lacked a solid research basis. Many massage schools still teach that only cancer patients who have been documented to be cancer-free for 5 years should be massaged. In the after-graduation world, many patients do not have that status, and the newly-graduated massage practitioner has been forced to decide, without guidelines, the appropriate way to balance the perceived risk of spreading cancer via metastasis against the benefit of providing needed pain or other symptom relief for the patient.

The effect: A guideline reviewing the evidence, taking into account the experience of practitioners "in the trenches" and the fact that most adverse events in the literature are single events and not necessarily directly related to the massage, would provide the massage practitioner with the following information: that, although the possibility of spreading cancer via metastasis provoked by massage has been hypothesized, it has never been conclusively demonstrated to occur in practice. However, many studies have demonstrated that massage provides relief for pain in cancer patients. Although these studies have some flaws in methodology, there is still a reasonable indication that massage is effective in reducing cancer pain and in reducing the quantity of pharmacologic painkillers required by cancer patients. Given the lack of evidence for the risk of metastasis from massage, and the demonstrated benefits, the ambiguity is resolved: the massage practitioner can reasonably conclude that providing palliative massage for the patient, in coordination with other members of the patient's health care team, is a way to proceed in the best interests of the patient.

In addition to the number of individual practitioner-client dyads that can be served by such guidelines, the profession of massage can benefit from the knowledge as well. By incorporating available information into an evidence-informed curriculum, schools can offer principles that are a closer fit to the realities of independent practice and can better prepare their students for making decisions when encountering such cases on their own.

\section{Scenario 2}

Because no accurate way to bill for evaluation and re-evaluation currently exists, the massage profession attempts to get new current procedural terminology (CPT) codes submitted for them. The proposal is rejected.
The need: The American Medical Association CPT committee rejects the code proposal because there are no practice guidelines indicating that evaluation is a common practice for massage practitioners. Massage practitioners continue to lack codes to bill for evaluation and re-evaluation.

The effect: Practice guidelines would be a helpful guide both to the profession and to other professions who work with massage in an interdisciplinary capacity in more thoroughly and realistically communicating clinical activities carried out by massage practitioners.

\section{Patients}

\section{Scenario 3}

A patient with a newly-diagnosed case of fibromyalgia wonders whether massage will be beneficial and whether there is any risk of massage making the pain worse.

The need: From the evidence cited in the guidelines and the criteria for determining improvement, the patient learns that the record on massage for fibromyalgia is mixed. The patient decides to have massage treatment on a trial basis. Based on the guidelines, the patient works out milestones with the practitioner at which they will decide whether to continue the massage, based on whether it seems to be working, having no effect, or making the pain worse.

The effect: Through access to the highest-quality information currently available, patients benefit under the ethical principles of autonomy (in making their own informed decisions about treatment) and beneficence (in knowing which treatments are likely to result in good outcomes for them).

\section{Other Health Care Practitioners}

\section{Scenario 4}

A physician's osteoarthritis patient requests, in addition to a pharmacologic treatment regimen, a referral for massage to treat pain and inflammation. The physician has a general concept of potential benefits from massage and is potentially willing to refer, but is also unsure of the type of massage, the frequency, and the duration for which to write the prescription. In addition, the referring physician may have concerns relating to medication and massage therapy interactions or therapeutic contraindications.

The need: The convergence of many factorsincluding the information explosion, the movement for patient autonomy, and the studies by Eisenberg et al. ${ }^{(1,2)}$ on use of CAM - has changed the landscape of medicine. Many physicians now are willing to try complementary medicine to see whether it can be a useful supplement to conventional treatments. However, most medical training does not contain sufficiently detailed information on the safety and efficacy of CAM to enable informed referral decisions. 
The effect: Giving other health care providers the specific information, in the form of a guideline starting point, about what is considered an appropriate norm of treatment will promote their comfort in prescribing it, both because the information will enhance their perception of the professionalism of massage as a discipline and because it will alleviate their concerns about making specific decisions in an area in which they do not have training or experience. For example, Persad advocates informing physicians and MTs alike regarding the need for caution in administering deep-tissue work on clients taking common over-the-counter nonsteroidal anti-inflammatories such as aspirin or ibuprofen. These medications used to treat pain and inflammation may also increase the risk of bruising ${ }^{(40)}$. Persad further notes that, because narcotic medications such as hydrocodone, morphine, and codeine (used to manage more severe pain) reduce the perception of pain, they may also substantially compromise a client's ability to provide accurate feedback to the therapist concerning appropriate pressure used in manipulating soft tissues ${ }^{(40)}$.

\section{Scenario 5}

A patient in the third trimester of her first pregnancy (carrying triplets) wants massage for the associated discomfort and increased back pain. She asks her nurse practitioner to prescribe it so that she can be reimbursed by her insurance company. The nurse practitioner is open to the idea, but is also concerned, because triplets are considered a high-risk pregnancy, and they are very likely to be born prematurely in any case. The concern over whether massage carries any increased risk in this situation and whether the patient will sue the nurse practitioner in the event of a bad outcome causes the nurse practitioner to hesitate in prescribing massage.

The need: In the absence of guidelines, the nurse practitioner, the patient and the massage practitioner are forced to make their best guesses about whether it is safe to provide massage in this situation, and if so, the type, the frequency, and the duration that should be used. In the risk-averse US medical culture that is a consequence of litigation, the patient will probably be turned away from massage, a decision that, while ensuring that some risky massages are not undertaken, also deprives patients in need of relief from safe massage treatments.

The effect: Appropriate guidelines would provide all parties with access to evidence on which to base decisions concerning indications and contraindication for this special population. Even if the nurse practitioner were to prescribe massage and an undesirable outcome were to result, the nurse practitioner would have the protection of the guidelines to show that all members of the health care team had operated according to established best practices. This approach would facilitate establishing that no negligence was involved on the part of the health care team.

\section{Regulatory Bodies}

\section{Scenario 6}

A state legislator deciding how to vote on a regulation about massage therapy scope of practice is the subject of political pressure from a lobbying group from a different manual therapy profession, who claim that a particular massage practice is really their domain and that MTs should be restrained from offering that treatment.

The need: Because massage therapy is regulated independently in the United States by legislators who have no special expertise in the scope of massage practice, regulatory decisions that affect the practice of massage are often made in a vacuum of objective information. Providing guidelines on accepted baselines of practice would serve as a benchmark for the legislators making these decisions.

The effect: Based on the guidelines, the legislator is able to distinguish whether the argument from the lobbying group is valid by determining whether the disputed treatment is part of the best practices agreed upon by the massage profession and other stakeholders and whether the treatment is generally accepted to be within the scope of massage practices. Relying on that independent verification of the validity of the argument, the legislator is accordingly able to cast a more informed vote on the issue.

\section{Third-Party Reimbursers}

\section{Scenario 7}

An insurance provider, newly mandated by the state to cover complementary and alternative treatments for insured patients, seeks evidence of the efficacy of massage for specific conditions and parameters for how much and how long to fund chosen treatments for the maximum likelihood of success.

The need: Given the allocation of resources by insurance companies, decisions about which complementary treatments to fund and the duration for which to fund them to expect a reasonable chance of success factor into decisions about how benefits are allocated to the insured.

The effect: The existence of guidelines outlining the types and duration of treatments for specific conditions and the evidence upon which those guidelines are based provide the insurance company with the information required to make decisions about the conditions for which massage could be used, and the duration and extent of massage treatment to reimburse.

\section{Researchers}

\section{Scenario 8}

A research principal investigator (PI) wants to study a research question that builds on previous studies to advance basic scientific knowledge of how massage works and how it can be applied in clinical practice. 
The PI consults the existing guidelines to determine the questions that have already been translated into best practices standards, the extent to which they have been studied, the evidence underlying those best practices, and the future avenues of study that indicate promising research questions.

The need: Past efforts in massage research have been scattered and uncoordinated, without necessarily having a direct connection to the clinical practice of massage. As more massage practitioners begin to move from research literacy to research capacity, a repository of existing clinical knowledge and the degree to which it is supported by the evidence can inform those research efforts and promote communication on the import of the research among members of the research team.

The effect: Guidelines provide a bridge between the research agenda and the expressed information needs of practitioners in the clinic. One of the features of a guideline process should be flagging of the contexts of practice in which guidelines would have particular effect (that is, prioritization) and for which the evidence base is currently inadequate. The PI would thus be able to choose from a direct list of research waiting to be tackled. The discussion base for existing guidelines would provide background information on any methodology issues previously raised in moving from research to guidelines, helping in research design. In this way, by providing a mechanism to highlight information that is well supported as compared with information in which gaps remain for activelypracticing massage practitioners, guidelines provide a feedback mechanism for the clinic to inform the laboratory, and vice versa.

\section{TRENDS IN HEALTH CARE GUIDELINES AND INFORMATICS}

In initiating the development of best practice guidelines for massage therapy relative to health care, the BPC strongly desires to assimilate existing well-accepted methodologies rather than to "reinvent the wheel.” Thus, initial effort has gone toward finding and noting the existing (extensive) literature on guideline development and practice competency. The relevant issues considered in the literature break into roughly four separate categories:

- Methodologies for the development and implementation of guidelines

- Outcome-based definitions of competence

- Credentialing and malpractice considerations for physicians referring to CAM providers

- Healthcare informatics

Although separate at first glance, these topics are interlinked by a health care quality initiative from the IOM, by a resultant process of health care selfreflection, and by extensive defense and technology industry efforts to create new capabilities and data standards for learning and competency communication and management. The review that follows highlights key papers and efforts in each of these categories.

\section{Methodologies for the Development and Implementation of Guidelines}

In November 1989, Congress amended the Public Health Service Act to create the Agency for Health Care Policy and Research (AHCPR). In turn, AHCPR requested advice from the IOM about how the agency might approach their new and challenging responsibilities for practice guidelines. Currently, the AHCPR has transformed into the Agency for Healthcare Research and Quality (AHRQ) ${ }^{(41)}$. The AHRQ maintains guidelines online, including links to the NGC and to other guideline agencies and resources, including an annotated bibliography on guideline development methodology.

One of the early results of the AHCPR effort was the report Clinical Practice Guidelines: Directions for a New Program, published by the National Academies Press in $1990^{(17)}$. A major conclusion of that report was that clinical guidelines should be founded on eight key principles:

- Validity: Practice guidelines are valid if, when followed, they lead to the health and cost outcomes projected for them, other things being equal. A prospective assessment of validity will consider the projected health outcomes and costs of alternative courses of action, the relationship between the evidence and recommendations, the substance and quality of the scientific and clinical evidence cited, and the means used to evaluate the evidence.

- Reliability/reproducibility: Practice guidelines are reliable and reproducible (1) if-given the same evidence and methods for guidelines developmentanother set of experts would produce essentially the same statements and (2) if-given the same circumstances - the guidelines are interpreted and applied consistently by practitioners or other appropriate parties. A prospective assessment of reliability may consider the results of independent external reviews and pretests of the guidelines.

- Clinical applicability: Practice guidelines should be as inclusive of appropriately defined patient populations as scientific and clinical evidence and expert judgment permit, and they should explicitly state the populations to which statements apply.

- Clinical flexibility: Practice guidelines should identify the specifically known or generally expected exceptions to their recommendations.

- Clarity: Practice guidelines should use unambiguous language, define terms precisely, and use logical, easy-to-follow modes of presentation.

- Multidisciplinary process: Practice guidelines should be developed by a process that includes par- 
ticipation by representatives of key affected groups. Participation may include serving on panels that develop guidelines, providing evidence and viewpoints to the panels and reviewing draft guidelines.

- Scheduled review: Practice guidelines should include statements about when they should be reviewed to determine whether revisions are warranted, given new clinical evidence or changing professional consensus.

- Documentation: The procedures followed in developing guidelines, the participants involved, the evidence used, the assumptions and rationales accepted, and the analytic methods employed should be meticulously documented and described.

Continuing on with their earlier work, the IOM launched, in 1996, a concerted, ongoing effort focused on assessing and improving the nation's quality of care. That initiative, Crossing the Quality Chasm: The IOM Health Care Quality Initiative ${ }^{(26)}$ is now in its third phase. The first phase of the initiative documented the serious and pervasive nature of the nation's overall quality problem, concluding that "the burden of harm conveyed by the collective impact of all of our health care quality problems is staggering." As part of the initiative, the IOM issued a series of reports that are causing self-reflection and reevaluation of health care education, of the definition and management of competence, and of provision of care.

\section{Outcome-Based Definitions of Competence}

Occurring in parallel with government agency efforts on clinical guidelines, other efforts have been directed toward defining outcome-based competencies for health care. These efforts have resulted in a number of publications and guides. Recognizing that medicine is taking on a global face, the Institute for International Medical Education (IIME) ${ }^{(42)}$ has developed a body of work on Global Minimum Essential Requirements ${ }^{(43)}$. This work has been summarized by the IIME Core Committee ${ }^{(44)}$ and by Wojtczak and Schwarz ${ }^{(45)}$.

In a coordinated effort with the Association of Medical Education in Europe (AMEE) ${ }^{(46)}$, a number of papers have been published both in the journal Medical Teacher and as AMEE guides. In particular, Harden ${ }^{(47)}$ introduced concepts of outcome-based education and Shumway and Harden ${ }^{(48)}$ introduced assessment of outcomes.

Also during this period, the Accreditation Council for Graduate Medical Education (ACGME) ${ }^{(49)}$ created the Outcome Project ${ }^{(50)}$, addressing outcome-based competency for physicians in the 21st century. A summary of the ACGME efforts on defining competency was published by Epstein and Hundert ${ }^{(51)}$ with an editorial comment by Leach ${ }^{(52)}$. Recently, Epstein ${ }^{(25)}$ added a detailed review of current thoughts on assessment in medical education. ACGME has noted that standards for professional competence delineate key technical, cognitive, and emotional aspects of practice, including those that may not be measurable. They defined six areas of competence and some means of assessing them:

- Patient care (including clinical reasoning)

- Medical knowledge

- Practice-based learning and improvement (including information management)

- Interpersonal and communication skills

- Professionalism

- Systems-based practice (including health economics and teamwork)

Several other agencies provide extensive guidance on the guidelines development process, with a considerable level of inter-knowledge existing between efforts. The Australian National Health and Medical Research Council (NHMRC) developed a protocol to guide the creation and implementation of clinical guidelines ${ }^{(53)}$. They derived nine basic principles for developing guidelines:

- Processes for developing and evaluating clinical practice guidelines should focus on outcomes. Outcome measures can range from survival rates to qualityof-life attributes.

- Clinical practice guidelines should be based on the best available evidence and should include a statement about the strength of their recommendations. Evidence can be graded according to its level, quality, relevance, and strength. The "level" of evidence refers to the study design used to minimize bias: the highest level involves a systematic review of randomized controlled clinical trials. "Quality" refers to the methods used to minimize bias in the design and conduct of a study. "Relevance" refers to the extent to which research findings can be applied in other settings. The "strength" of evidence relates to the magnitude and reliability of the treatment effect seen in clinical studies: strong effects are more likely to be real and more likely to be clinically important. Ideally, recommendations would be based on the highest level of evidence, but this may be difficult to achieve in public health and social science interventions.

- The method used to synthesize the available evidence should be the strongest applicable. Taking the evidence - of whatever level, quality, relevance, or strength - and turning it into a clinically useful recommendation depends on the judgment, experience, and good sense of the group developing the guidelines. The fact of having evidence from a high-level study does not automatically result in a good clinical recommendation.

- The process of guideline development should be multidisciplinary and should include consumers. If guidelines are to be relevant, those who are expected to use them or to benefit from their use should play a part in their conception and development. Involv- 
ing a range of generalist and specialist clinicians, allied health professionals, experts in methodology, and consumers will improve the quality and continuity of care and will make it more likely that the guidelines will be adopted.

- Guidelines should be flexible and adaptable to varying local conditions. They should include evidence relevant to various target populations and geographic and clinical settings, take into account costs and constraints, and make provision for accommodating the different values and preferences of patients.

- Guidelines should be developed with resource constraints in mind. They should incorporate an economic appraisal, which may be helpful for choosing between treatment options.

- Guidelines are developed to be disseminated and implemented taking into account their target audiences. They should also be disseminated in such a way that practitioners and consumers become aware of them and use them.

- The implementation and effect of guidelines should be evaluated.

- Guidelines should be revised regularly.

Subsequent to their earlier report, the NHMRC released a document to inform external persons and bodies of the procedures to be followed in developing guidelines that are intended for submission to the NHMRC for approval ${ }^{(54)}$. This document includes flowcharts summarizing the process. In the United Kingdom, the National Institute for Health and Clinical Excellence also developed a guidelines development manual ${ }^{(55)}$. The AGREE (Appraisal of Guidelines Research and Evaluation) Collaboration has created the AGREE Instrument to help unify the approach to guideline creation and implementation across Europe $^{(56)}$. The Scottish Intercollegiate Guidelines Network (SIGN) also provides guidelines and, as one of their guidelines, maintains the Guidelines Developer's $H_{\text {Handbook }}{ }^{(57)}$. The introduction to the SIGN handbook contains concise flowchart summaries of the guideline development process and lifecycle.

A significant number of individual papers from different domains of health practices deal with guideline development. Shekelle et al. ${ }^{(58)}$ discuss guideline development to ensure desired patient outcomes, based on a combination of the literature about guideline development and the results of their combined experience in guideline development in North America and Britain. Their paper considers five steps in the initial development of an evidence-based guideline. Thomas describes the development, implementation, and appraisal of clinical practice guidelines for nursing(59). She notes that, while "most of the development and evaluation of clinical guidelines has occurred in the field of medicine, nurses are becoming more interested in the use of guidelines as one means of facilitating evidence-based practice.” Eccles and Grimshaw provide a succinct review of criteria for guideline selection and presentation ${ }^{(60)}$.
Raine et al. ${ }^{(61)}$ investigated cognitive factors affecting group consensus in creating guidelines. They note that "the nominal group technique is a method of eliciting and aggregating judgments in a transparent and structured way. It can provide important information on levels of agreement between experts. However, conclusions can be at odds with the published literature. If they are, reasons need to be explicit.” Grilli et al. raise concerns about the quality, reliability, and independence of practice guidelines created by specialty societies ${ }^{(62)}$. They note that such guidelines often fail to follow accepted methodologic criteria.

Writing from a chiropractic perspective, Mootz and Hansen discussed the use and understanding of what they term "clinical algorithms"(63). We note that their use of algorithm differs from general scientific usage ${ }^{(64)}$, in which an algorithm is taken to be a procedural recipe that includes allowance for repetition and branches - in short, any definite procedure for solving a problem or performing a task, independent of its specific form of presentation. Mootz and Hansen's use of algorithm as a graphical format would more generally be taken as the presentation of an algorithm as a graphical flowchart. The more widely used terminology will be used here to facilitate interdisciplinary understanding. It generalizes Mootz and Hansen's statement that "algorithms" offer providers and health care administers a "sense of predictability and a systematic organization to case management," making it information-dependent rather than specific to a graphical format. As a specific example, it would include capturing guidelines within the Guidelines Element Model (GEM) ${ }^{(65)}$. It generalizes the decision tree from a representation as a flowchart to a more general concept of a "graph" as an abstract structure of interconnections ${ }^{(66)}$.

\section{Credentialing and Malpractice Considerations}

Eisenberg et al. ${ }^{(11)}$ examined a number of issues related to credentialing of CAM providers, including massage providers. Several short articles by Parkman discussed credentialing issues ${ }^{(67-70)}$. All of these are general considerations, lacking discussion of any specific outcomes for massage. Also in general, a report by Alderson and Montesano prepared for the Ontario Health Professions Regulatory Advisory Council, extensively reviewed the basis and means for regulation, deregulation, and changing scopes of practice of health care professions ${ }^{(71)}$. This report was part of a general review and updating of the 1991 Regulated Health Professions Act. Gowan-Moody and Baskwill presented a Canadian perspective on credentialing specific to massage therapy ${ }^{(29)}$.

Studdert et al. presented insurance claim data for massage, chiropractic, and medicine ${ }^{(10)}$. For the period 1993 to 1996 reported for massage, the Studdert et al. data indicate average annual massage claims of 1.8 per 1000 insured and 0.79 claims paid per 1000 insured, with an average payment of about $\$ 6400$. The break- 
down of claims were $61 \%$ minor injuries, $6 \%$ injuries above minor, $14 \%$ sexual misconduct, and 19\% "nonphysical" or "other." As a raw comparison, annual claims for chiropractic and medicine respectively averaged 26 and 94 per 1000 insured. The rates reported for massage by Studdert et al. are supported by two review papers. Ernst and Grant separately looked at the extremely rare reports of harm from massage in the medical literature ${ }^{(13,14)}$. The conclusions of both reviews are well characterized by Ernst's statement that although "massage is not entirely risk free, serious adverse events are probably true rarities.” Batavia examined the state of massage contraindications, noting lack of agreement between sources and a general lack of ties to any original basis or paper ${ }^{(38)}$.

Cohen and Eisenberg addressed malpractice liability issues associated with CAM provision ${ }^{(12)}$. They based their discussion on a four-cell table based on independent determination of safety and efficacy. In this framework, the papers by Studdert et al. ${ }^{(10)}$, Ernst ${ }^{(13)}$, and Grant ${ }^{(14)}$ would indicate that efficacy for specific conditions and contexts will be the larger consideration for massage therapy, coupled with practitioner abilities for communication and for working as part of a health care team. Cohen and Ernst et al. have both looked at ethical issues arising within CAM provision ${ }^{(72,73)}$.

A number of papers have examined the balance and paradox of combining objective evidence with other considerations of practice. Epstein and Hundert included communication skills and team skills within their definition of competence ${ }^{(51)}$. Egnew explored, from a medical perspective, the issues of healing that transcend the application of technique ${ }^{(74)}$. These issues have also been explored by cardiologist Bernard Lown ${ }^{(31)}$. Weissman commented on two papers that he feels embody both sides of the medical coin ${ }^{(75)}$. Welch and Lurie discussed the teaching of evidence-based medicine ${ }^{(76)}$. Branch discussed medical education and the ethics of caring ${ }^{(77)}$. In two papers, Hewitt-Taylor looked at the definition and balance of evidence related to nursing care ${ }^{(78,79)}$. In the conclusion of the latter paper, she specifically notes this balance:

Despite the benefits of clinical guidelines and care protocols, these have the potential to lead to inappropriate levels of standardization in which individual client contexts and professional autonomy and judgment are impeded.... Clinical guidelines should be seen as general recommendations, not absolutes that must be followed in all situations. They are a part, not the entirety, of nursing care provision and should influence decision making in the presence of clinical expertise and the ability to assess and evaluate individual patient needs in the light of available resources."

\section{HEALTH CARE INFORMATICS}

The guidelines process we are working to create is occurring within a larger framework of rapidly evolv- ing efforts in formalizing concepts of learning objects and competency management. Such efforts, similar to the development of the Internet, are being driven by a consortium of government agencies, the business sector, and the educational community. One such effort, initiated in 1998 by the US Defense Department, is the Advanced Distributed Learning (ADL) initiative ${ }^{(80)}$. One of the results of ADL is the Shareable Content Object Reference Model (SCORM) ${ }^{(81)}$, which defines a means of referencing "learning objects" so that they can be shared for multiple purposes and between multiple users. The purpose of SCORM is to establish a common framework for delivering learning tools and content on a global basis and to serve as a forum for cooperative research, development, and assessment of new learning technology prototypes. All new Defense Department e-learning must conform to SCORM.

Already, SCORM and other efforts in creating standards for interchange of learning information are being woven into international academic collaborations to create complex learning environments such as Moodle $^{(82)}$ and the Sakai project ${ }^{(83)}$. The cumulative effect of such efforts is likely to revolutionize our concepts of the provision of learning information and assessment of competency to an extent as great as the Internet has changed our concept of information communication. The Internet, as a matter of history, had its genesis in a 1969 project of the Defense Advanced Research Projects Agency to create a decentralized (and thus attack-resistant) communications network.

The current initiatives are driven by a need for far more time- and resource-effective ways of managing learning to manage knowledge, skills, and abilities for task performance. In the long term, guidelines would provide baseline guidance on performance of treatment, leading to consideration of cognitive tasks and kinesthetic skills used in such performance. The following developments may facilitate anticipation of learning gaps and appropriate learning modules for practitioners providing treatment. This, however, is a consideration much further down the road than the more immediate task of defining a process for guideline creation and validating that process by the creation of several specific guidelines. Still, a quick look at emerging standards for learning and competency data is revealing. A number of the standards were created by the IEEE Learning Technology Standards Committee (LTSC) working groups ${ }^{(84)}$.

The IEEE 1484.12.1 - 2002 standard for learning object metadata ${ }^{(85)}$ is an internationally-recognized open standard for the description of "learning objects"(86). This view looks at course modules that can be shared by multiple learning providers in multiple contexts.

Reusable competency definitions (RCDs) ${ }^{(87)}$ define a universally acceptable competency definition model to allow for the creation, exchange and reuse of competency definitions in applications such as learning management systems, competency or skill gap analysis, and learner competency profile management. 
The late Claude Ostyn, who headed the IEEE working group on RCDs, also proposed a standard for simple reusable competency maps $(\mathrm{SRCMs})^{(88)}$. These SRCMs can reference other SRCMs and RCDs, with the addition of required proficiency levels for an RCD. Thus SRCMs would provide a means of building a competence description for complex tasks or job descriptions involving multiple competencies with required proficiency levels. As a feasibility demonstration, Ostyn also provided an example of gleaning RCDs from the US O*Net occupational database ${ }^{(89)}$.

Technological standards for learning and competency management are rapidly finding their way into health care informatics. For instance, MedBiquitous, a consortium of the medical education community, included a discussion of use of these standards in their 2005 annual report ${ }^{(90)}$. The MedBiquitous Consortium is a nonprofit organization accredited by the American National Standards Institute to create standards to support health care education and training, professional competence assessment, certification, licensure, professional and scientific publications, and health care professional online communities and portals. MedBiquitous includes a number of working groups, including those for professional profile data standards and health care competency data standards ${ }^{(91)}$. The mission of the MedBiquitous Competencies Working Group is to develop XML (eXtensible Markup Language) standards and supporting guidelines for competency data so that educational resources and activities can be tied to a competency framework. The mission of the MedBiquitous Professional Profile Working Group is to develop XML standards and web services descriptions to enable the exchange of clinician profile information across organizations and systems.

As part of MedBiquitous, Hersh et al. reported their efforts to facilitate access to competencies and e-learning content in the medical informatics domain $^{(92,93)}$. They conclude that such information-sharing standards can be successfully used and that their implementation in other domains is warranted.

The take-home message from the above efforts is that creating a process for massage therapy guidelines creation is not happening in isolation. The effort is cognizant of and standing on the shoulders of many other processes occurring in domains of competency and proficiency management, both within and beyond domains of health care. We can expect to learn from the experience and use the procedures and tools developed by others. In the larger context of the rapidly developing world of 21st century health care informatics, our effort to coalesce massage therapy clinical experience and research-based knowledge into guidelines for treatment is a modest effort.

\section{A PROCESS FOR GUIDELINE DEVELOPMENT}

One of the general challenges in creating guidelines comes in eliciting needs, knowledge, problems, and solutions from expert stakeholders. Although later reviews add wider input and discussion, the initial input creates the framework. If we are to bring experts together and use their experience effectively, a process that keeps them involved in active discussion is needed. The World Café is such a process ${ }^{(94)}$. It is consistent with methodology suggested by Crandall et al. for eliciting the actual use of cognitive and perceptual skills ${ }^{(9)}$ :

One of the most powerful knowledge elicitation methods available to Cognitive Task Analysis (CTA) practitioners is to probe actual incidents. People tell us about all kinds of details, challenges, subtle cues, background influences, and strategies that might never come to light in a general interview or a controlled situation. Skilled decision makers have had many different experiences; that's how they formed their knowledge and honed their skills. Their stories can be a doorway into that experience.

The use of stories to effectively elicit tacit information and to further communicate such information is also supported by Klein ${ }^{(24)}$ and by the studies and observations of Brown on technical repair sociology ${ }^{(95)}$. In particular, the World Café is a structured method for engaging experts in the type of problem-oriented dialog and story creation discussed by Brown ${ }^{(95)}$.

The World Café work has developed a set of seven design principles as a means of intentionally fostering conversation:

- Set the context

- Create hospitable space

- Explore questions that matter

- Encourage everyone's contribution

- Cross-pollinate and connect diverse perspectives

- Listen together for patterns, insights, and deeper questions

- Harvest and share collective discoveries

These simple principles, when used in combination, provide useful guidance for anyone seeking creative ways to foster authentic dialog in which the goal is thinking together and creating actionable knowledge.

The World Café process uses a series of discussions at small tables. One person acts as host at each table, and the others progress through a series of discussion at various tables. The tables are small to draw out discussion. Progression between tables crosspollinates ideas between tables. Each table has a white paper cover and available crayons to help visualize ideas. After a series of progressions, each table host summarizes the ideas and discussions from their table.

As a conversational process, the World Café is an innovative yet simple methodology for hosting conversations about questions that matter. These conversations link and build on each other as people move between groups, cross-pollinate ideas, and discover new insights into the questions or issues that are most important in their 
life, work, or community. As a process, the World Café can evoke and make visible the collective intelligence of any group, thus increasing people's capacity for effective action in pursuit of common aims. By including a diversity of experience and viewpoints in those attending, the concept space being addressed can be thoroughly explored. The World Café has been used by hundreds of groups, including large multinational corporations, small nonprofits, government offices, community-based organizations, and educational institutions. Several examples best illustrate such use.

Delaney et al. used the World Café process to elicit issues and stimulate dialog in nursing education ${ }^{(96)}$. Hess et al. used the World Café to explore the purpose and goals of a nursing board subcommittee ${ }^{(97)}$. Miles et al. reported use of the World Café in working with stakeholders to form a corporate social responsibility strategy ${ }^{(98)}$. Turk and Peterson used the World Café in working with state agencies and other stakeholders to further colorectal screening programs ${ }^{(99)}$. Wagenaar reviewed the World Café process from the perspective of knowledge management and development ${ }^{(100)}$. While et al. reported use of the World Café for two conferences to facilitate provision of cross-boundary child health services ${ }^{(101)}$. In 2003-2004 a series of multi-agency meetings on redesigning nursing education in California were based on the World Café(102). The California Institute for Nursing and Health Care was later awarded a grant from the Moore Foundation to facilitate post-conference analysis and reporting ${ }^{(103)}$. Finally, the University of California-Santa Cruz informational technology (IT) services department used a series of World Café conferences to define the purpose, core values, and envisioned future of the department through the involvement of stakeholders, IT department leadership, and campus management ${ }^{(104)}$. This last example is notable for having made available many of the photographed drawings from the cafés.

Using small flash-memory recorders, we can capture the discussions on massage therapy guidelines that occur on each treatment topic area. Transcripts of these discussions can subsequently be made available as part of the documentation basis for conclusions coming from the symposium and review. Still photos of table drawings and larger group presentations and discussions will also be captured as part of the process documentation.

The BPC envisions testing and refining a guidelines creation process beginning with the convening of a symposium with 35 to 50 experts, drawn from various experience viewpoints. This symposium would use the World Café model and work on developing draft guidelines for three conditions commonly presenting to MTs: stress management, low back pain, and lymphedema. These conditions were selected also because they represent variety in the existing support in the current literature. Although the resulting guidelines have substantial merit in themselves, the BPC's emphasis here is on vetting the guideline process rather than on the specific guidelines chosen.
The support processes that will occur preceding and following the symposium will be as important to the credibility and transparency of the result as will the symposium itself. To use the symposium time effectively, some pre-symposium education of participants on the methodology and specific goals will be required. It will also be important to solicit knowledge of important research literature from participants in advance and to ensure that this research basis is available to the participants as a whole sufficiently in advance of the symposium.

Following the symposium will come the work of creating transcripts of recorded discussions, mapping elicited concepts ${ }^{(9)}$, and synthesizing collected information into draft guidelines that cogently capture ideas that emerged during the symposium, points of concern that were raised, and the resolutions that occurred. The process should result in a synthesis and summary of concepts and knowledge (that is, concept mapping and knowledge management), but will not necessarily result in a single consensus of opinion. The synthesis and background documentation will then be made available to symposium participants to review for completeness and accuracy. Following this internal review, the draft guidelines and underlying basis in documentation will then opened for wide review and comment. An RFC would be issued by various media to all stakeholders.

In this review process, the BPC is aided by developments in technology and can follow protocols used by a number of public agencies. It is now common to make documents available for review over the Internet, soliciting RFCs by e-mail, traditional mail, and publication in trade journals. Sufficient review time must be allowed for stakeholders to become aware of the review through these several means. During the review period, comments would be collected by web form, e-mail, fax, and traditional mail. Use of a web form has generally been encouraged by other agencies using this process, because the resulting comments can be formatted for further processing with little extra intervention. Depending on the nature of the comments and the extent of the resulting changes to the guidelines, multiple iterations of this process would likely be needed. The comments themselves would become part of the guideline documentation base. The initial guideline creation process would end with submission of the guidelines to the NGC. However, the NGC criteria require that guidelines be reviewed and updated every 5 years. Such reviews will be facilitated by keeping a thorough record of the discussions and comments on which guidelines were originally based. The best location for this documentation archive is as yet undetermined, although it could potentially occur through collaboration with an academic health care informatics department. The BPC members are aware of earlier collaborations of this nature, such as a current collaboration between Northwestern Health Sciences University (NWHSU) and the University of Minnesota to facilitate the practice of evidence-based health care 
by CAM practitioners. That effort is integrating University of Minnesota expertise in information management with NWHSU experience in CAM curricula.

Ultimately, it will be the totality, transparency, and rigor of the creation process that will lend credibility to the guidelines. The process proposed herein is for creating guidelines strongly conforming to the protocols presented in Field and $\mathrm{Lohr}^{(17)}$. The description in this section is considered by the BPC to be a beginning, not an end. It will evolve as new information and assessments become available, such as the just-released IOM report Knowing What Works in Healthcare ${ }^{(105)}$. The conceptual framework of that effort well matches our own:

The committee based its work on the central premise that decisions about the care of individual patients should be based on the conscientious, explicit and judicious use of current best evidence. This means that individual clinical expertise should be integrated with the best information from scientifically-based systematic research and applied in light of the patient's values and circumstances. Focusing decision-making on the patient is integral to improving the quality of health care; it is also imperative if consumers are to take an active role in making informed health care decisions based on known risks and benefits. This report also recognizes that health care resources are finite. Thus, setting priorities for systematic assessment of scientific evidence is essential.

\section{CONCLUSIONS}

The efforts of the BPC are, to a large extent, still a work in progress, but several features are clearly emerging from the committee's efforts to this point. The BPC has found that there are existing efforts and criteria in other areas of health care from which the massage therapy profession can learn and on which it can draw. There is an existing and extensive literature. Existing criteria set standards for the processes of creation, documentation, peer review, and regular revisiting of guidelines. The existence of the NGC provides both a target set of guideline criteria and a means of disseminating guidelines as they are created. Importantly, guidelines are defined as a flexible means to frame and extend existing individual experience and knowledge. They are a beginning point - an additional resource for decisionmaking - rather than an end in themselves.

It also is clear that multiple stakeholders and multiple contexts would benefit from having evidence-based guidelines with the credibility of a multidisciplinary peer review behind them. Adiscussion on CAM credentialing is continuing to evolve apart from efforts by the massage therapy profession. In addition, the wider health care system is undergoing a continuing process of selfreflection and re-definition, in part spurred by a series of IOM reports. Changes in health care informatics and use of technology to manage training and competency are present and accelerating. Such changes provide both tools and challenges for the profession.

The BPC has envisioned a process for guideline creation and an intent to test that process on creation of guidelines for stress management, low back pain, and lymphedema. The World Café process provides a structured means of holding discussions and capturing ideas through a symposium of experts drawn from a diversity of experience and perspectives. Bringing that symposium into being and ensuring the proper data handling and review processes remains a challenge to be bridged, particularly in the context of the fundraising required and the current economic downturn. Yet, the process has started. This first report to the profession, outlining our learning and thoughts to date, is the first tangible result and, hopefully, the beginning of a discussion. We invite your letters to the editor.

\section{ACKNOWLEDGMENTS}

The authors express their appreciation to the Board of Trustees of the Massage Therapy Foundation for their faith and support in enabling this work. We extend our particular thanks to Alison Pittas and Gini Ohlson for their efforts in smoothing logistics and keeping us on track and on task. We also appreciate the University of Washington informatics students who took the time to participate in part of our March 2007 meeting and to provide us with their insights. Lastly, the views and opinions expressed here are the authors' own; they do not necessarily represent the policies or positions of the Massage Therapy Foundation.

\section{REFERENCES}

1. Eisenberg DM, Kessler RC, Foster C, Norlock FE, Calkins DR, Delbanco TL. Unconventional medicine in the United States-prevalence, costs, and patterns of use. New Engl $J$ Med. 1993;328(4):246-252.

2. Eisenberg DM, Davis RB, Ettner SL, et al. Trends in alternative medicine use in the United States, 1990-1997: results of a follow-up national survey. JAMA. 1998;280(18):1569-1575.

3. Barnes PM, Powell-Griner E, McFann K, Nahin RL. Complementary and alternative medicine use among adults: United States, 2002. Adv Data. 2004;(343):1-19.

4. Associated Bodywork and Massage Professionals. Massage Therapy Fast Facts. MassageTherapy.com website. http:// www.massagetherapy.com/_content/images/Media/ Factsheet1.pdf. Published July 2007. Accessed June 19, 2008.

5. American Massage Therapy Association. 2008 Massage Therapy Industry Fact Sheet. American Massage Therapy Association website. http://www.amtamassage.org/pdf/ 2008IndustryFactSheet.pdf. Published 2008. Accessed June 19, 2008.

6. Esmail N. Complementary and Alternative Medicine in Canada: Trends in Use and Public Attitudes, 1997-2006. Vancouver, 
BC: Fraser Institute; 2007.

7. Sherman KJ, Cherkin DC, Kahn J, et al. A survey of training and practice patterns of massage therapists in two US states. BMC Complement Altern Med. 2005;5:13.

8. Sherman KJ, Cherkin DC, Deyo RA, et al. The diagnosis and treatment of chronic back pain by acupuncturists, chiropractors, and massage therapists. Clin J Pain. 2006;22(3):227-234.

9. Crandall B, Klein G, Hoffman RM. Working Minds-A Practitioner's Guide to Cognitive Task Analysis. Cambridge, MA: MIT Press; 2006.

10. Studdert DM, Eisenberg DM, Miller FH, Curto DA, Kaptchuk TJ, Brennan TA. Medical malpractice implications of alternative medicine. JAMA.. 1998;280(18):1610-1615.

11. Eisenberg DM, Cohen MH, Hrbek A, Grayzel J, Van Rompay MI, Cooper RA. Credentialing complementary and alternative medical providers. Ann Intern Med. 2002;137(12):965973.

12. Cohen MH, Eisenberg DM. Potential physician malpractice liability associated with complementary and integrative medical therapies. Ann Intern Med. 2002;136(8):596-603.

13. Ernst E. The safety of massage therapy. Rheumatology (Oxford). 2003;42(9):1101-1106.

14. Grant KE. Massage safety-injuries reported in Medline relating to the practice of therapeutic massage-1965-2003. $J$ Bodywork Mov Ther. 2003;7(4):207-212.

15. National Guideline Clearinghouse. Home page. National Guideline Clearinghouse website. http://www.guideline.gov. Published 1998. Updated June 16, 2008. Accessed June 22, 2008.

16. Institute of Medicine. Home page. National Academy of Sciences website. http://www.iom.edu. Published 2008. Accessed June 23, 2008.

17. Field MJ, Lohr KN, eds. Clinical Practice Guidelines: Directions for a New Program. Committee to Advise the Public Health Service on Clinical Practice Guidelines, Institute of Medicine. Washington, DC: National Academy Press; 1990.

18. The Pew Charitable Trusts. Home page. Pew Charitable Trusts website. http://www.pewtrusts.org. Published 1996. Updated 2008. Accessed August 7, 2008.

19. Rand Corporation. Home page. Rand Corporation website. http://www.rand.org. Published 1994. Updated 2008. Accessed August 7, 2008.

20. Benner P. From Novice to Expert: Excellence and Power in Clinical Nursing Practice. Menlo Park, CA: Addison Wesley; 1984.

21. Benner P. Using the Dreyfus model of skill acquisition to describe and interpret skill acquisition and clinical judgment in nursing practice and education. Bull Sci Technol Soc. 2004;24(3):188-189.

22. Dreyfus SE, Dreyfus HL. A Five-Stage Model of the Mental Activities Involved in Directed Skill Acquisition. US Air Force Operations Research Center Report ORC-80-2. Berkeley, CA: University of California; 1980. http://handle.dtic.mil/100.2/ ADA084551. Accessed August 11, 2008.

23. Dreyfus HL, Dreyfus SE. Mind Over Machine: The Power of Human Intuition and Expertise in the Era of the Computer. New York, NY: Free Press; 1986.

24. Klein G. Sources of Power: How People Make Decisions. Cambridge, MA: MIT Press; 1998.

25. Epstein RM. Assessment in medical education. $N$ Engl $J$ Med. 2007;356(4):387-396.
26. Institute of Medicine. Crossing the Quality Chasm: The IOM Health Care Quality Initiative. Institute of Medicine website. http://www.iom.edu/CMS/8089.aspx. Published n.d. Updated July 20, 2006. Accessed June 22, 2008.

27. Mager RF, Pipe P. Analyzing Performance Problems. Atlanta, GA: CEP Press; 1997.

28. Rosen R. On Becoming a Profession: The Challenges and Choices That Will Determine Our Future. Siler City, NC: Rick Rosen; 2008. http://www.massagemag.com/Magazine/ R.Rosen\%20white\%20paper.pdf. Accessed August 11, 2008.

29. Gowan-Moody D, Baskwill A. Report on Policy Issues Concerning the Regulation of Massage Therapy in Canada. Toronto, ON: Federation of Massage Therapy Regulatory Authorities of Canada; 2006. http://www.cmto.com/pdfs/ FOMTRAC_Report_May_06.pdf. Accessed August 11, 2008.

30. Mindell A. Metaskills: The Spiritual Art of Therapy. Tempe, AZ: New Falcon Pubublications; 1995.

31. Lown B. The Lost Art of Healing. New York, NY: Ballantine Books; 1999.

32. Ornstein RE, Sobel D. Healthy Pleasures. Reading, MA: Addison-Wesley; 1990.

33. Ornstein R, Sobel DS. The Healing Brain: Breakthrough Discoveries About How the Brain Keeps Us Healthy. 2nd ed. Cambridge, MA: Malor Books; 1999.

34. Rossi EL. Psychobiology of Mind-Body Healing: New Concepts of Therapeutic Hypnosis. 2nd ed. New York, NY: WW Norton \& Company; 1993.

35. Melzack R. Pain: past, present and future. Can J Exp Psychol. 1993;47(4):615-629.

36. Blakeslee S, Blakeslee M. The Body Has a Mind of Its Own. New York, NY: Random House; 2007.

37. Hawkins J, with Blakeslee S. On Intelligence. New York, NY: Times Books; 2007.

38. Batavia M. Contraindications for therapeutic massage-do sources agree? J Bodywork Mov Ther. 2004;8(1):48-57.

39. Corbin L. Safety and efficacy of massage therapy for patients with cancer. Cancer Control. 2005;12(3):158-164.

40. Persad RS. Massage Therapy and Medications: General Treatment Principles. Toronto, ON: Curties-Overzet Publications; 2001.

41. Agency for Healthcare Research and Quality (AHRQ). Home page. AHRQ website. http://www.ahrq.gov. Published n.d. Accessed August 8, 2008.

42. Institute for International Medical Education (IIME). Home page. IIME website. http://www.iime.org. Published 1999. Updated 2008. Accessed August 8, 2008.

43. Institute for International Medical Education (IIME). Global Minimum Essential Requirements. IIME website. http:// www.iime.org/gmer.htm. Published 1999. Updated 2008. Accessed August 8, 2008.

44. Core Committee, Institute for International Medical Education. Global minimum essential requirements in medical education. Med Teach. 2002;24(2):130-135. http:// www.iime.org/documents/gmer.htm. Accessed August 11, 2008.

45. Wojtczak A, Schwarz MR. Minimum essential requirements and standards in medical education. Med Teach. 2000;22:555559. http://www.iime.org/documents/vs.htm. Accessed August 11, 2008. 
46. Association of Medical Education in Europe (AMEE). Home page. AMEE website. http://www.amee.org. Published 2007. Updated July 30, 2008. Accessed August 8, 2008.

47. Harden RM. AMEE Guide No. 14. Outcome-based education. Part 1: An introduction to outcome-based education. Med Teach. 1999;21(1):7-14.

48. Shumway JM, Harden RM. AMEE Guide No. 25. The assessment of learning outcomes for the competent and reflective physician. Med Teach. 2003;25(6):569-584.

49. Accreditation Council for Graduate Medical Education (ACGME). Home page. ACGME website. http://www.acgme.org. Published 2000. Updated 2008. Accessed August 8, 2008.

50. Accreditation Council for Graduate Medical Education (ACGME). ACGME Outcome Project. ACGME website. http://www.acgme.org/Outcome. Published 2000. Updated 2008. Accessed August 8, 2008.

51. Epstein RM, Hundert EM. Defining and assessing professional competence. JAMA. 2002;287(2):226-235.

52. Leach DC. Competence is a habit. JAMA. 2002;287(2):243-244.

53. National Health and Medical Research Council (NHMRC). A Guide to the Development, Evaluation and Implementation of Clinical Practice Guidelines. Canberra, Australia: NHMRC; 1999. http://www.nhmrc.gov.au/publications/synopses/_files/ cp30.pdf. Accessed August 11, 2008.

54. National Health and Medical Research Council (NHMRC). NHMRC Standards and Procedures for Externally Developed Guidelines. Canberra, Australia: NHMRC; 2005. http:// www.nhmrc.gov.au/publications/synopses/_files/nh56.pdf. Accessed August 11, 2008.

55. National Institute for Health and Clinical Excellence (NICE). Clinical Guideline Development Methods. NICE website. http:/ /www.nice.org.uk/aboutnice/howwework/developingniceclinic alguidelines/clinicalguidelinedevelopmentmethods/ clinical_guideline_development_methods.jsp. Published 2007. Accessed June 22, 2008.

56. AGREE (Appraisal of Guidelines for Research and Evaluation) Collaboration. AGREE Instrument Training Manual. AGREE Collaboration website. http://www.agreecollaboratio n.org/pdf/aitraining.pdf. Published January 2003. Accessed August 11, 2008.

57. Scottish Intercollegiate Guidelines Network (SIGN). SIGN 50: A Guideline Developer's Handbook. SIGN website. http:// www.sign.ac.uk/guidelines/fulltext/50/index.html. Published 2001. Updated January 2008. Accessed June 22, 2008.

58. Shekelle PG, Woolf SH, Eccles M, Grimshaw J. Clinical guidelines—developing guidelines. BMJ. 1999;318(7183):593-596.

59. Thomas L. Clinical practice guidelines. Evid Based Nurs. 1999;2(2):38-39.

60. Eccles MP, Grimshaw JM. Selecting, presenting and delivering clinical guidelines: are there any “magic bullets”? Med J Aust. 2004;180(6 Suppl):S52-S54.

61. Raine R, Sanderson C, Hutchings A, Carter S, Larkin K, Black N. An experimental study of determinants of group judgments in clinical guideline development. Lancet. 2004;364(9432):429-437.

62. Grilli R, Magrini N, Penna A, Mura G, Liberati A. Practice guidelines developed by specialty societies: the need for a critical appraisal. Lancet. 2000;355(9198):103-106.

63. Mootz RD, Hansen DT. Understanding and appropriate use of clinical algorithms. In: Mootz RD, Hansen DT, eds. Best
Practices in Clinical Chiropractic. Sudbury, MA: Jones and Bartlett; 1999: xiv-xxiv.

64. Wikipedia. Algorithm. http://en.wikipedia.org/wiki/Algorithms. Wikipedia website. Published n.d. Updated August 6, 2008. Accessed August 8, 2008.

65. Shiffman RN. Guidelines Element Model (GEM). GEM website. http://gem.med.yale.edu. Updated February 24, 2008. Accessed June 23, 2008.

66. Wikipedia. Graph (mathematics). Wikipedia website. http:// en.wikipedia.org/wiki/Graph_\%28mathematics\%29. Published n.d. Updated July 30, 2008. Accessed August 8, 2008.

67. Parkman CA. CAM's struggle for legitimacy. Case Manager. 2004;15(1):22-24.

68. Parkman CA. Issues in credentialing CAM providers. Case Manager. 2004;15(4):24-27.

69. Parkman CA. Initiatives for credentialing CAM practitioners. Case Manager. 2004;15(5):19-21.

70. Parkman CA. Regulatory issues in CAM. Case Manager. 2004;15(6):26-29.

71. Alderson D, Montesano D. Regulating, De-regulating and Changing Scopes of Practice in the Health Professions: A Jurisdictional Review. Ottawa, ON: Health Professions Regulatory Advisory Council; April 2003. http://www.oaccpp.ca/ news/appendix1-dp.pdf. Accessed August 11, 2008.

72. Cohen MH. Legal and ethical issues in complementary medicine: a United States perspective. Med J Aust. 2004;181(3):168-169.

73. Ernst E, Cohen MH, Stone J. Ethical problems arising in evidence based complementary and alternative medicine. $\mathrm{J}$ Med Ethics. 2004;30(2):156-159.

74. Egnew TR. The meaning of healing-transcending suffering. Ann Fam Med. 2005;3(3):255-262.

75. Weissman SH. The need to teach a wider, more complex view of "evidence". Acad Med. 2000;75(10):957-958.

76. Welch HG, Lurie JD. Teaching evidence-based medicine: caveats and challenges. Acad Med. 2000;75(3):235-240.

77. Branch WT. The ethics of caring and medical education. Acad Med. 2000;75(2):127-132.

78. Hewitt-Taylor J. Reviewing evidence. Intensive Crit Care Nurs. 2003;19(1):43-49.

79. Hewitt-Taylor J. Clinical guidelines and care protocols. Intensive Crit Care Nurs. 2004;20(1):45-52.

80. Advanced Distributed Learning (ADL). Home page. ADL website. http://www.adlnet.gov. Published 2007. Updated June 9, 2008. Accessed June 19, 2008.

81. Advanced Distributed Learning (ADL). SCORM (Shareable Content Object Reference Model). ADL website. http:// www.adlnet.gov/scorm. Published 2007. Updated June 9, 2008. Accessed June 19, 2008.

82. Moodle. Home page. Moodle website. http://moodle.org. Published n.d. Accessed June 22, 2008.

83. Sakai. Home page. Sakai website. http://sakaiproject.org. Published n.d. Accessed June 22, 2008.

84. IEEE Learning Technology Standards Committee (LTSC). Home page. LTSC website. http://ieeeltsc.org. Published 2004. Updated April 22, 2008. Accessed June 22, 2008.

85. IEEE Learning Technology Standards Committee (LTSC). Learning Object Metadata, WG12. LTSC website. http:// www.ieeeltsc.org/working-groups/wg12LOM. Published 2004. Updated November 27, 2007. Accessed June 22, 2008. 
86. Wikipedia. Learning Object Metadata. Wikipedia website. http:/ /en.wikipedia.org/wiki/Learning_object_metadata. Published n.d. Updated May 1, 2008. Accessed June 22, 2008.

87. IEEE Learning Technology Standards Committee (LTSC). Competency Data Standards, WG20. LTSC website. http:// www.ieeeltsc.org/working-groups/wg20Comp. Published 2007. Updated April 22, 2008. Accessed June 22, 2008.

88. Ostyn C. Proposed Draft Standard for learning TechnologySimple Reusable Competency Map. Rev 4. Ostyn Consulting website. http://www.ostyn.com/standardswork/competency/ ReusableCompMapProp.pdf. Published February 22, 2006. Accessed August 11, 2008.

89. Ostyn C. Competency Data Standards Resources. Ostyn Consulting website. http://www.ostyn.com/rescompetency.htm. Published 2006. Accessed June 22, 2008.

90. MedBiquitous. Annual Report 2005. MedBiquitous website. http://www.medbiq.com/about_us/annual_report/MedBiqAnn ualReport2005.pdf. Published 2006. Accessed August 11, 2008.

91. MedBiquitous. Home $>$ Working Groups. MedBiquitous website. http://www.medbiq.org/working_groups/index.html. Published 2001. Updated August 16, 2006. Accessed June 22, 2008.

92. Hersh WR, Bhupatiraju RT, Greene PS, Smothers V, Cohen C. A standards-based approach for facilitating discovery of learning objects at the point of care. AMIA Annu Symp Proc. 2005;2005:979. http://www.pubmedcentral.nih.gov/ articlerender.fcgi?artid=1560826. Accessed August 11, 2008.

93. Hersh WR, Bhupatiraju RT, Greene PS, Smothers V, Cohen C. Adopting e-learning standards in health care: competency-based learning in the medical informatics domain. AMIAAnnu Symp Proc. 2006;2006:334-338. http://www.pubmedcentral.

nih.gov/articlerender.fcgi?artid=1839696. Accessed August 11, 2008.

94. Brown J, Isaacs D, World Café Community. The World CaféShaping Our Futures Through Conversations That Matter. San Francisco, CA: Berrett-Koehler Publishers; 2005. [See also http:/ /www.theworldcafe.com]

95. Brown JS. CGU Home $>$ About CGU $>$ Commencement $>$ Historical Information > Remarks by John Seeley Brown: Honorary Degree Recipient and Commencement Speaker. Claremont Graduate University website. http:// www.cgu.edu/pages/1528.asp. Published n.d. Accessed June 26, 2008.

96. Delaney C, Daley K, Lajoie D. Facilitating empowerment and stimulating scholarly dialogue using the World Café Model. $J$ Nurs Educ. 2006;45(1):46.
97. Hess DR, Everett G, Tuchmann L, Dossey BM. Holistic nurses and the New Mexico board of nursing: integrative practices subcommittee formation, development, and activities. $J$ Holist Nurs. 2006;24(2):132-138.

98. Miles MP, Munilla LS, Darroch J. The role of strategic conversations with stakeholders in the formation of corporate social responsibility strategy. J Bus Ethics. 2006;69(2):195-205.

99. Turk E, Peterson KJ. Colorectal cancer: The Cancer Research and Prevention Foundation's dialogue for action. J Oncol Pract. 2006;2(2):93-94.

100. Wagenaar S. Book review. The World Café. Shaping Our Futures Through Conversations That Matter. KM4D J. 2006;2(1):128-133. http://www.km4dev.org/journal/index.php/ km4dj/article/view/59. Accessed August 11, 2008.

101. While A, Murgatroyd B, Ullman R, Forbes A. Nurses', midwives' and health visitors' involvement in cross-boundary working within child health services. Child Care Health Dev. 2006;32(1):87-99.

102. California Institute for Nursing and Health Care (CINHC). Creating the Nursing Future Through Shared Vision and Voices: Final Executive Summary. http://www.cinhc.org/programs/documents/WorldCafeReport.pdf. CINHC website. Published January 2004. Accessed August 11, 2008.

103. Boller J. California Institute for Nursing and Health Care Receives Grant from Gordon and Betty Moore Foundation to Study Nursing Education Redesign in California. Press release. Gordon and Betty Moore Foundation website. http:// www.moore.org/newsitem.aspx?id=1948. Published January 16, 2007. Accessed June 24, 2008.

104. University of California-Santa Cruz, Information Technology Services. Home $>$ IT Transformation Program $>$ News and Events > IT World Cafe. University of California website. http://its.ucsc.edu/transformation/news_and_events/ worldcafe.php. Published n.d. Accessed June 24, 2008.

105. Eden J, Wheatley B, McNeil B, Sox H, eds. Knowing What Works in Health Care: A Roadmap for the Nation. Washington, DC: The National Academies Press; 2008. http://www.nap.edu/ catalog.php?record_id=12038. Accessed August 11, 2008.

Corresponding Author: Keith Eric Grant, 1814 Harvest Road Pleasanton, CA 94566-5417 USA E-mail: keg@ramblemuse.com

Funding for this project was provided by the Massage Therapy Foundation, 500 Davis Street, Suite 900, Evanston, IL 60201 USA (www.massagetherapyfoundation.org). 